\title{
Preliminary Collapse Simulation of a Reinforced Concrete Flat Plate Substructure Using Spring Connection Modelling
}

\author{
Huizhong Xue ${ }^{1, a}$, Hong Guan ${ }^{1, b}, \mathrm{Yi} \mathrm{Li}^{2, \mathrm{c}}$ \\ ${ }^{1}$ Griffith School of Engineering, Griffith University Gold Coast Campus, QLD4222, Australia \\ ${ }^{2}$ Beijing University of Technology, Beijing, 100124, China \\ ${ }^{a}$ xue.hz@live.cn \\ bh.guan@griffith.edu.au \\ cyili@bjut.edu.cn
}

Keywords: Numerical modelling; Flat plate; Punching shear; Progressive collapse; Spring connection.

\begin{abstract}
To investigate progressive collapse behavior of reinforced concrete (RC) flat plate structures, a reliable and efficient numerical approach is developed in this study using spring connection modelling. This connection unit aims to simulate complicate punching shear behavior at critical regions surrounding the columns. Five springs are used as the connection elements: two for flexural and integrity steel bars and three for concrete contributions. The flexural and integrity steel bars embedded in the columns are modeled explicitly, which enables the model to present the structural behavior post punching shear failure. Bending and shear actions are represented by two concrete springs. The third concrete spring is assigned axial action property to restrain two end nodes of the connection on the model. In particular, the punching shear spring controls the connection unit when punching shear failure occurs. To apply the connection unit, the regions of slab-column connections are partitioned from the slab regions according to the critical shear surfaces. Then the connection unit links two corresponding nodes on the two edges formed from the partition. A physical experiment of a RC flat plate substructure under progressive collapse is simulated. Result comparison demonstrates that the numerical model has the capability to capture the structural behavior in progressive collapse. However, further improvement of the modelling technique is necessary to enhance numerical accuracy.
\end{abstract}

\section{Introduction}

The concept of progressive collapse of structures has been put forward for decades. In recent years, this topic has been brought up to a prevalent level largely due to terrorist attacks which caused progressive collapse with a great loss. Engineers and researchers attempt to establish a set of progressive collapse resistance strategies to mitigate the risk of progressive collapse and its serious outcomes. Before developing prevention methodologies and design provisions, sound understanding of collapse mechanisms is necessary. Extensive research on progressive collapse of framed structures have been conducted. However those related to RC flat plate structures are still lacking. The structural feature of load-bearing flat plate systems, without beams involved, offers benefits in some aspects while also brings shortcomings of being vulnerable to punching shear failure. Although various punching shear failure prediction formulas have been proposed, the influences that some critical parameters may bring to the structures in progressive collapse remain unclear. Numerical investigation is both feasible and cost-effective to study the failure mechanisms in progressive collapse caused by punching shear. This paper summarises relevant research achievements and aims to develop a numerical model using the spring connection unit. A published physical experiment is simulated using the proposed model. Good agreement is achieved between the experimental and 
numerical results. To enhance numerical accuracy in simulating the post-failure behavior, further improvement to the modelling technique will be made in future study.

\section{Backgrounds}

Progressive collapse can be defined as a disproportionate failure which is initiated from a local damage of a structure due to unexpected loads and then propagates to other portions of the structure, finally leading to a total collapse that is not proportional to the initial local damage [1]. The causes leading to the initial local damage can be various. Moreover, this chain-effect featured failure terminates when the unbalanced loads are fully redistributed to attain an equilibrium, usually giving high consequences: life and property loss.

Except the unpredictability and high consequences, two structural characteristics of progressive collapse are also notable: large deformation and global featured behavior. The investigation of progressive collapse focuses on the "post-failure" stage of the traditional punching shear analyses. In progressive collapse, almost all of the structural elements associated with the collapse portions are beyond the limit state. Because of concrete cracking and steel yielding or breaking, large deformation is exhibited. Once a local failure occurs, if the interactions between structural elements cannot bear the redistributed loads which are originally taken by the initially failed elements, failure propagates to other portions of the structure. Not only the initially failed elements but a large number of interconnecting elements are also involved in the progressive collapse, making it a global behavior of the whole structure.

RC flat plate structures are inherently more vulnerable to progressive collapse as it has compromises in offering structural continuity and ductility [1,2]. It is confirmed that the most problematic area provoking progressive collapse in a RC flat plate structure is located at an interior slab-column joint where punching shear failure may probably occur [2]. To understand its failure mechanisms, some physical experiments as well as numerical analyses have been carried out. In particular, several achievements on numerical modelling of $\mathrm{RC}$ flat plate structures in progressive collapse have been made. A 2D model containing springs [3] shows the feasibility and conveniences of using springs representing structural behaviors at regions of slab-column joints. A macro model using connector beam elements [4] provides the idea of partitioning and splitting the slab and then linking the slab blocks together using connectors in a 3D manner. The explicit modelling of reinforcement in flat plate structures [5] reveals the significant role that steel bars play in "post" punching shear failure stage. In this study, a 5-spring connection unit model is developed based on the strengths of the existing work.

\section{Modelling}

Slab Modelling. A slab has a noticeable geometric feature in that its thickness is far less than its other two orthogonal dimensions. Consequently, it can be processed as a planar component. Given its material formation, it is reasonable to employ multi-layer elements to model a slab. Distinguished concrete layers and reinforcement layers are bounded together to form a slab.

Column Modelling. In a typical punching shear failure, the column penetrating the slab is undamaged and remains in its original position. In this study, columns are modeled using two-node beam elements.

Reinforcement Modelling. To investigate the structural performance of the continuous reinforcement after punching shear failure, the steel bars are modeled explicitly. The continuous reinforcement consists of two parts: the top steel bars required to resist bending are marked as flexural reinforcement; the bottom steel bars required to resist progressive collapse are marked as integrity reinforcement. For other steel bars which do not interact with columns, they are modeled as reinforcement layers incorporated into the multi-layer elements for the slab. 
Slab-column Joints Modelling. The regions of slab-column joint, which are in cone-shape forms, are not damaged. In several structural engineering design codes (China, US, Australia, etc.), the critical shear surfaces encompassing the cone-like concrete punching core are specified. This is illustrated in Fig.1a. The critical shear surfaces initiate from the intersecting points of the bottom surface of the slab and the column surface, i.e. points A and A'. Then they propagate in 45 degrees through the slab, reaching the top surface of the slab, points B and B'. As a result, the concrete punching core are bounded by the two surfaces A-B and A'-B'. Yet, as the slab is modeled using 2D layered elements, the thickness of the slab cannot be represented in the numerical model. Therefore, the mid-depth points $\mathrm{C}$ and $\mathrm{C}^{\prime}$ on the critical shear surfaces are taken as the connecting points between the slab-column joint region and the remaining slab.

5-Spring Connection Unit Modelling. Having the slab-column joint regions partitioned, the next step is to consider the connections between the slab-column joint regions and the remaining slab. The connecting elements are most critical to reflect the structural behavior of the model in punching shear. Two groups of springs are used to model the connections: concrete springs and reinforcement springs. The concrete springs are used to link the concrete components between the slab-column joint region and the remaining slab. More specifically, three concrete springs are adopted to model axial, bending, and shear actions. The bending and shear actions are the main mechanical actions developed on punching shear surfaces. On the other hand, the axial action spring is set to horizontally bond the two nodes on the two surfaces. Appropriate stiffness must be assigned to the springs representing relevant structural actions, that is, the force-displacement relationship must be assigned to axial and shear springs; whereas moment-rotation relationship must be assigned to bending springs. For reinforcement, two springs are used to connect the flexural and integrity steel bars to the slab-column joint regions. Due to the fact that steel bars are under axial actions, force-displacement relationship of steel is assigned as stiffness of these two springs. The 5-spring connection unit linking the slab-column joint region and remaining slab is shown in Fig.1b.

(a)

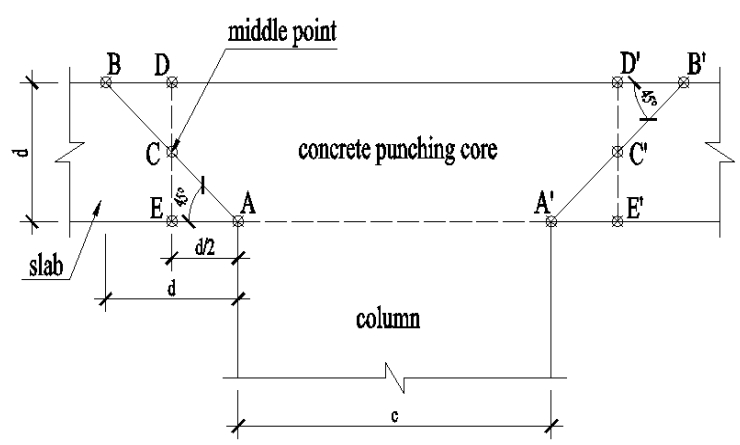

(b)

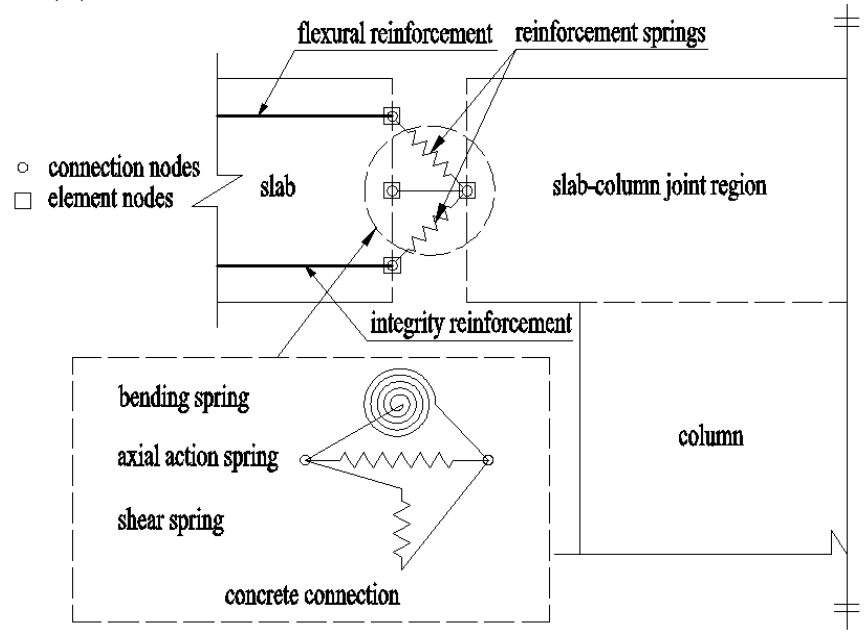

Fig.1 (a) Cross Section of Slab-Column Joint Region (b) 5-Spring Connection Unit

Other Modelling Concerns. For the material property, bilinear constitutive models [6] are assigned for the steel and concrete. MSC.Marc nonlinear finite element analysis software is adopted for the modelling task.

\section{Simulation and Results}

A physical experiment of a reinforced concrete flat plate substructure [7] in progressive collapse is simulated herein. Due to symmetry of the specimen, only the quarter model is analysed (Fig. 2a). The load-displacement relationships obtained from the experiment and the numerical analysis is 
compared in Fig. 2b. Good agreement is achieved. The largest discrepancy is found to be in between displacements $15 \mathrm{~mm}$ and $30 \mathrm{~mm}$, corresponding to the elastic-plastic stage. The numerical model also overestimate the stiffness as compared to the experiment. In addition, in the experiment, the vertical displacement of interior column finally reached $90 \mathrm{~mm}$, whereas the numerical prediction is $82 \mathrm{~mm}$. This indicates that the numerical model also overestimates the load-bearing capacity.

(a)

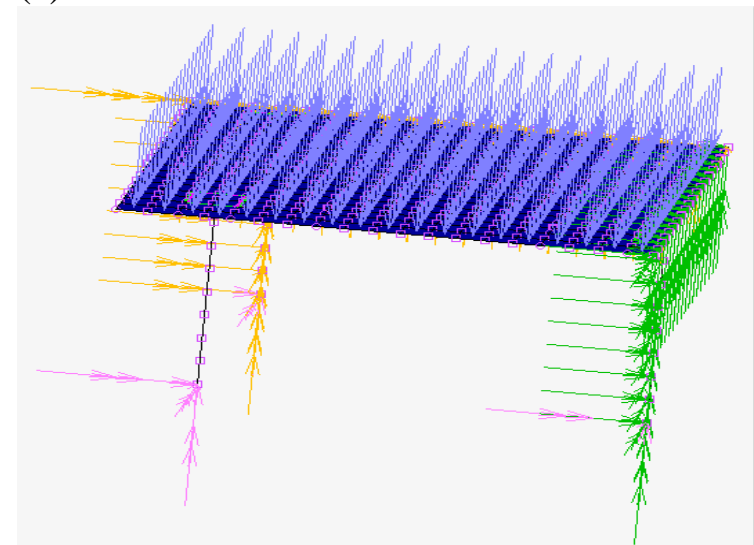

(b)

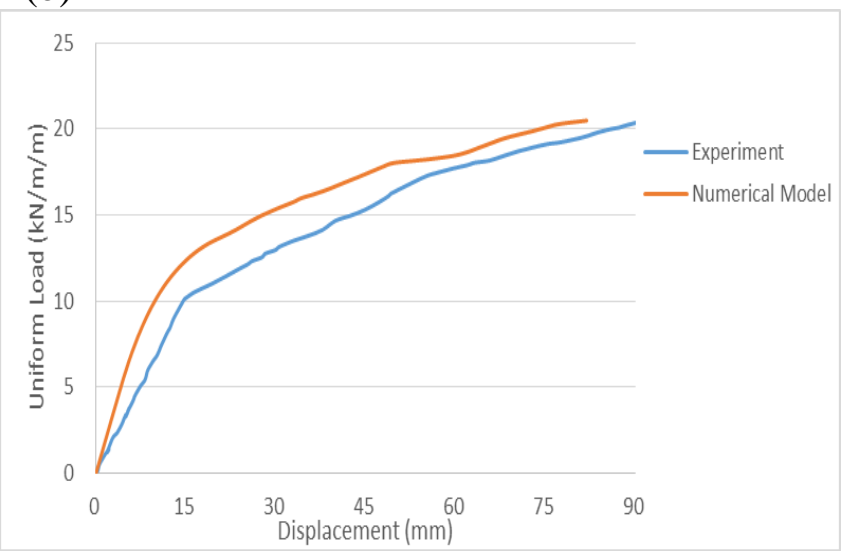

Fig.2 (a) The Finite Element Model (b) Comparison of Load-displacement Relationships

\section{Conclusion}

Based on the existing achievements in numerical modelling of flat plate substructures, this study develops a 5-spring connection unit model. The results show that it has the capability to simulate complicated punching shear behavior, although the numerical accuracy needs to be further improved. The improvements can be considered from following aspects: appropriate material stiffness and its decrease pattern, the deactivation timing of the connection unit and including flexural failure concerns into the flat plate model.

\section{References}

[1] Ellingwood, B. R. (2006). Mitigating Risk from Abnormal Loads and Progressive Collapse. Journal of Performance of Constructed Facilities, 20(4), 315-323.

[2] Hawkins, N. M., \& Mitchell, D. (1979). Progressive Collapse of Flat Plate structures. ACI Journal, 76(7), 775-808.

[3] Kang, T. H., Wallace, J. W., \& Elwood, K. J. (2009). Nonlinear Modeling of Flat-plate Systems. Journal of Structural Engineering, 135(2009), 147-158.

[4] Liu, J. R., Tian, Y., \& Orton, S. L. (2013). Vulnerability of Disproportionate Collapse in Older Flat Plate Buildings Subjected to Sudden Removal of A Bearing Column. Structures Congress, 2013.

[5] Keyvani, L., Sasani, M., \& Mirzaei, Y. (2014). Compressive Membrane Action in Progressive Collapse Resistance of RC Flat Plates. Engineering Structures, 59(2014), 554-564.

[6] Lu, X. Z., Ye, L. P., \& Liao, Z. W. (2009). Elasto-plastic Analysis of Buildings against Earthquake - Theory Model and Implementation on Abaqus, MSC.Marc, and SAP 2000. Beijing, China: China Architectures \& Building Press.

[7] Yi, W. J., \& Zhang, F. Z. (2012). Experimental Study on Collapse Performance of a RC Flat Plate Frame Structure. Journal of Building Structures, 33(6), 35-41 